$\xi=-1$

\title{
Factors associated with hemodialysis adequacy among end stage renal disease patients on maintenance hemodialysis in Rwanda
}

\author{
Didace Ndahayo $^{1 *}$, Emmanuel Bimenyimana Gapira ${ }^{1}$, Theos Mbabazi ${ }^{2}$, Geldine Chironda ${ }^{3}$ \\ ${ }^{1}$ Msc, Is A Clinical Nurse Specialist Working at Rwanda Military Hospital in Kigali, Rwanda. The Research Work Was Done While He \\ Was A Student at University of Rwanda, College of Medicine and Health Sciences, School of Nursing and Midwifery, Kigali, Rwanda \\ ${ }^{2}$ Msc, Is A Hospital Duty Coordinator Working at University Teaching Hospital of Butare, Rwanda. The Research Work Was Done \\ While He Was A Student at University of Rwanda, College of Medicine and Health Sciences, School of Nursing and Midwifery, Kigali, \\ Rwanda \\ 3. Phd, Is A Lecturer and Post-Doctoral Research Fellow at University of Kwazulu-Natal, College of Health Sciences, School of Nursing \\ and Public Health, Howard College Campus, Durban, South Africa. The Research Work Was Done When Dr Geldine Chironda Was A \\ Training Specialist Employed By New York University, Rory Meyers School of Nursing, New York, USA And University of Rwanda, Col- \\ lege of Medicine and Health Sciences, Rwanda \\ *Corresponding author E-mail: didasdidace@gmail.com
}

\begin{abstract}
The aim of this study was to assess the factors associated with dialysis adequacy in ESRD patients on maintenance hemodialysis in Rwanda. A descriptive cross-sectional study was conducted. A sample size of 66 hemodialysis patients was selected using purposive sampling strategy. An interview scheduled guide was used to collect data. Dialysis adequacy was calculated using kt/v Daugirdas \& Schneditz formula. The mean hemodialysis adequacy was $1.26 \pm 0.34$. Most participants $[41(62 \%)]$ had optimal hemodialysis adequacy of equal or greater than to 1.2, $19(29 \%)$ had near optimal hemodialysis adequacy $(0.8-1.2 \mathrm{kt} / \mathrm{v})$ and only $6(9 \%)$ had less than optimal hemodialysis adequacy $(\mathrm{kt} / \mathrm{v}<0.8)$. Factors associated with hemodialysis adequacy were hospital settings $(\mathrm{p}=.010)$, age $(\mathrm{p}=.007)$, BMI $(\mathrm{p}=.004)$ and blood pressure level $((\mathrm{p}=.018)$. Moreover, mode of transport and type of drinking water was significantly associated with hemodialysis adequacy ( $p=0.032$ and 0.030 respectively). In conclusion, the level of hemodialysis adequacy was low in 38\% of ESRD patients with associated factors predominantly demographics. Therefore, further research inquiry is needed on additional factors which include technical aspects to establish their association with hemodialysis adequacy.
\end{abstract}

Keywords: End Stage Renal Disease; Hemodialysis Adequacy; Rwanda.

\section{Introduction}

The term End Stage Renal Disease (ESRD) refers to chronic kidney disease treated with either dialysis or kidney transplantation (Shibiru et al. 2013). Hemodialysis (HD) is the dialysis modality used for about $90 \%$ of patients globally and the mainstay therapy which is offered for ESRD patients who cannot undergo renal transplantation (Lu et al. 2018). The main purpose of HD is the provision of sufficient and safe patient treatment which contributes to better physical condition of the patient thus preventing further problems and complications that arise due to uremia (Chauhan \& Mendonca 2015).

Hemodialysis adequacy (HDA) is an independent, significant factor in improving ESRD patients' quality of life and is measured using $\mathrm{Kt} / \mathrm{V}$ and URR (urea reduction rate) in which Blood Urea Nitrogen (BUN) is measured before and after HD treatment (Daugirdas \& Schneditz 2015). British renal association (BRA) and Canadian Society of Nephrology (CSN) recommended a KT/V of 1.2 for three times hemodialysis per week and URR of more than 65\% (Shahdadi et al. 2017). Furthermore, a URR of less than 65\% is associated with increased morbidity and mortality among patients (Nahid et al. 2016). Maintaining the adequacy of hemodialysis remains one of the challenges in the provision of hemodialysis treatment process. Hence the study is being carried out to assess the hemodialysis adequacy of patients on maintenance HD in Rwanda.

End Stage Renal Disease (ESRD) is a global burden and the leading cause of morbidity and mortality with prevalence rising from 4.7 million in 2010 to 9.7 million in 2015 (Thaminda et al. 2015). In 2017, one in ten worldwide had been reported to have CKD which progressively leads to ESRD in its last stage (Marcia 2017). In Africa like the rest of the world, the needs of renal care are increasing but the lack of renal registries hide from view of reliable statistics on the prevalence of ESRD. The recent review of ESRD in Sub Saharan Africa (SSA) reported 13.9\% prevalence of ESRD (Adremi et al. 2017), Rwanda accounts for approximately 10 to $15 \%$ of the prevalence of ESRD patients (Mukakarangwa et al. 2018).

A patient with ESRD needs two or three HD sessions in a week for survival (Fujisaki et al. 2018) and these sessions are expected to achieve the required adequacy. High-adequacy dialysis may ameliorate uremic side effects such as malnutrition, fluid overload, and 
bleeding and mitigate its complications (Shahdadi et al. 2017). However, clinical experiences have shown that adequacy among hemodialysis patients is minimal and no study has been done to attest this in Rwanda. In other literatures, a study done in Egypt by (Sheikh and Ghazaly 2016) revealed inadequate HD dose among $60 \%$ of population involved on their study whilst in Sudan 58\% were labeled as having adequate solute clearance with URR of not less than 65\% (Hisham \& Mazin 2015).

There are many factors that have been found to be associated with dialysis adequacy and this includes age, gender, social economic status, the type of vascular access, dialyzer type, the dose and rout of erythropoietin stimulation agents (ESA) used (Hamid \&Fatemeh2013, Klaric et a. 2016, Nahid et al. 2016). Moreover, Salwa et al. (2015) proved minimal hemodialysis adequacy with non-adherence which further results in significant impaired of quality of life among the ESRD patients. Patients receiving sub-optimal dose of hemodialysis have increased morbidity and mortality (Fernández et al. 2017). Moreover, inadequate HD is common and is associated not only in poor patient survival, but also leads to anemia, malnutrition, functional impairment and frequent hospitalization that culminate in an increased health care cost and increased mortality rate (Chijiokee et al. 2016).

Again, a negative impact on the quality of life (QOL) of ESRD patients on maintenance HD is also apparent as a result of dialy sis inadequacy (Marta et al. 2018). HD remains the renal replacement modality for the majority in Rwanda as a SSA country (Naicker 2015). This modality is mainly offered in four referral hospitals and in two small stand-alone private clinics. Hence there is a need to make sure that hemodialysis adequacy is reached. Since as to date, no study has been done to establish the level of dialysis adequacy and its associated factors in all centers providing hemodialysis in Rwanda. Therefore, the purpose of the study was to assess the factors associated with hemodialysis adequacy in ESRD patients on maintenance HD in Rwanda.

\section{Methods}

\subsection{Research design}

This study was descriptive cross section design in nature. This design studied- helped to establish the factors associated with hemodialysis adequacy in ESRD patients on maintenance HD in Rwanda.

\subsection{Study setting}

This study was conducted in the four referral hospitals in Rwanda. Rwanda is sovereign state in central and east Africa and one of the smallest countries on the African continent. The country has a health care system that is decentralized on multi-tiered system. The current study was conducted in referral hospitals that are the Rwanda Military Hospital, Centre Hospitalière et Universitaire de Kigali (CHUK), King Faisal Hospital (KFH), Centre Hospitalière et Universitaire de Butare (CHUB). This modality is mainly offered in public and private tertiary referral hospital only whilst another private hemodialysis unit is still under developing.

\subsection{Population}

The populations for this study were the ESRD patients on maintenance HD in Rwanda. Delimitation of the population to a homogenous level group was achieved through inclusion and exclusion criteria.

\subsection{Inclusion and exclusion criteria}

In the present study stable patients with signed informed written consent, a confirmed diagnosis of ESRD, age above 18 years old, and being on maintenance hemodialysis for a minimum period of (3) three months were recruited. This study ruled out unstable patients, patients with acute kidney injury, those who refused to sign the consent form, all younger than 18 years old as well as those who have been dialyzed less than 3 months.

Table 1: Demographic Data of Study Participants (N=66)

\begin{tabular}{ll}
\hline Demographic variables & Frequency (\%) \\
\hline Hospital origin of the participants & $8(12)$ \\
Hospital i & $7(11)$ \\
Hospital ii & $31(47)$ \\
Hospital iii & $20(30)$ \\
Hospital iv & \\
Gender distribution in participants & $47(71)$ \\
Males & $19(29)$ \\
Females & $11(17)$ \\
Age group of the participants & $13(20)$ \\
18 to 30 years & $15(23)$ \\
31 to 40 years & $14(21)$ \\
41 to 50 years & $13(20)$ \\
50 to 60 years & \\
Greater than 60 years & $8(12)$ \\
BMI of the participants & $46(70)$ \\
Under weight & $12(18)$ \\
Normal weight & $0(\%)$ \\
Overweight & \\
Obese & \\
Marital status of the participants & $41(62)$ \\
Married & $17(26)$ \\
Single & $1(2)$ \\
Divorced & $5(8)$ \\
Separated & $2(3)$ \\
\hline Widowed & \\
\hline
\end{tabular}




\begin{tabular}{|c|c|}
\hline \multicolumn{2}{|l|}{ Education level of the participants } \\
\hline Uneducated & $1(2)$ \\
\hline Primary & $31(47)$ \\
\hline Secondary & $24(36)$ \\
\hline College /university & $10(15)$ \\
\hline \multicolumn{2}{|l|}{ Religion distribution of participants } \\
\hline Christian & $62(94)$ \\
\hline Muslim & $3(4)$ \\
\hline Traditional & $1(2)$ \\
\hline \multicolumn{2}{|l|}{ Occupation of the participants } \\
\hline Self employed & $14(21)$ \\
\hline Skilled worker & $7(11)$ \\
\hline Unemployed & $44(67)$ \\
\hline Student & $1(1)$ \\
\hline \multicolumn{2}{|l|}{ Monthly income of the participants } \\
\hline 0 to $5000 \mathrm{Rwf}$ & $20(30)$ \\
\hline 51 to $10000 \mathrm{Rwf}$ & $19(29)$ \\
\hline 101000 to $200000 \mathrm{Rwf}$ & $15(23)$ \\
\hline \multicolumn{2}{|l|}{ Medical support system of the participants } \\
\hline Community based health insurances & $6(9)$ \\
\hline Government /private medical insurance & $45(68)$ \\
\hline Family/Friends/NGOs & $13(20)$ \\
\hline Self-sponsored & $2(3)$ \\
\hline \multicolumn{2}{|l|}{ Residence area of the participants } \\
\hline Low density & $15(23)$ \\
\hline Medium density & $29(44)$ \\
\hline High density & $13(20)$ \\
\hline Commune or rural & $9(13)$ \\
\hline \multicolumn{2}{|l|}{ Means of transport for the participants } \\
\hline Public mean of transport & $44(67)$ \\
\hline Private means of transport & $22(33)$ \\
\hline \multicolumn{2}{|l|}{ Previous area of residence for the participants } \\
\hline 0 to $10 \mathrm{Km}$ & $10(15)$ \\
\hline 11 to $20 \mathrm{Km}$ & $8(12)$ \\
\hline 21 to $40 \mathrm{Km}$ & $25(38)$ \\
\hline 0 to $10 \mathrm{Km}$ & $27(41)$ \\
\hline 11 to $20 \mathrm{Km}$ & $9(14)$ \\
\hline 21 to $40 \mathrm{Km}$ & $22(33)$ \\
\hline Far of $40 \mathrm{Km}$ & $8(12)$ \\
\hline \multicolumn{2}{|l|}{ Sources of drinking water for the participants } \\
\hline Tape water & $45(68)$ \\
\hline Packed water & 21(32) \\
\hline \multicolumn{2}{|l|}{ Causes of ESRD for the participants } \\
\hline Hypertension & $26(39)$ \\
\hline Diabetes mellitus & $21(31)$ \\
\hline Gromerulonephritis & $5(8)$ \\
\hline Others (malaria, unknowns, PKD and HIVAN) & $14(22)$ \\
\hline \multicolumn{2}{|l|}{ Time on hemodialysis of the participants } \\
\hline Between 4 months to one year & $21(32)$ \\
\hline Between one year to two years & $29(44)$ \\
\hline Between two years to five years & $8(12)$ \\
\hline More than five years & $5(8)$ \\
\hline After a graft rejection & $3(4)$ \\
\hline
\end{tabular}

\subsection{Sample size}

In this study the entire population was very small; therefore, it was reasonable to base on the census population. This allows gathering information about the general population, in order to present a full and reliable picture of the population. Therefore, the initial expected sample size was 90 ESRD patients on maintenance HD. However, not only financial constraints led to irregularity in dialysis treatment in these settings but also some of patients died and others dropped out during the time of data collection. With these constraints, the researcher was left with a sample size of 66 ESRD patients maintained on hemodialysis treatment.

\subsection{Sampling strategy}

This study used a non-probability sampling method, purposive sampling technique to purposively select ESRD participants on maintenance hemodialysis. The type of purposive sampling used was total population where the whole population of consented ESRD participants was used in the study. In this study, all ESRD patients shared the same specific attributes/traits which include the same diagnosis, modality of treatment, exposure to same procedure, challenges and almost the same lifestyle modification.

\subsection{Data collection instrument}

An interview scheduled guide was used to collect data. The tool was developed through in-depth literature review and consisted of (3) three sessions namely demographic characteristics, level of hemodialysis adequacy and hemodialysis adequacy factors that consist of 
clinical profile, therapy related, patient's knowledge, health care providers and adherence to hemodialysis factors. Hemodialysis adequacy was calculated using kt/v Daugirdas \& Schneditz formula (Daugirdas \& Schneditz, 2015).

\subsection{Validity and reliability of Instrument}

Polit and Beck, (2012) define validity of a questionnaire as the degree to which the instrument measures what it is intended to measure. However not only face validity that was maintained but also content was assured and content validity ratio was calculated at 0.8 , whereas the construct validity was checked as well. A reliability analysis called Cronbach's alpha was performed to measure the internal consistency of the study's instrument. However, the item- by -item Cronbach's alpha was computed calculated and gave value of 0.67 which was acceptable for the internal consistency of the instrument.

\subsection{Ethical considerations}

Ethical clearance and permission reference No: CMHS/IRB/079/2019 from the College of Medicine and Health Sciences research committee, Ref No: RMH/IRB/017/2019 was obtained from Rwanda Military Hospital, Ref No: EC/CHUK/058/2019 from Centre Hospitalière et Universitaire de Kigali and Ref No: CHUB/DG/SA/05/0815/2019 from Centre Hospitalière et Universitaire de Butare and a permission from KFH were obtained before data collection. Right to self-determination, privacy, confidentiality and fair treatment was observed during data collection. Participant authorization and informed consent was sought.

\subsection{Data analysis}

Data was coded and entered into SPSS version 21 in preparation for analysis. Descriptive statistical methods and inferential statistics of chi square and multiple regressions were used to analyze the data. Descriptive statistics used to describe the demographic variables, to establish level of HDA among ESRD patients on maintenance HD, to present the factors that contribute to hemodialysis adequacy. Inferential statistics of chi square and multiple regressions used to test any association between demographic variables, and other factors to hemodialysis adequacy in ESRD patients in Rwanda.

\section{Results}

\subsection{Demographic characteristics}

Table 1 reveals the demographic characteristics of study participants. A total of 66 patients were included in the study. Forty-seven $(71 \%)$ were males and nineteen $(29 \%)$ were females. Many of them $59(90 \%)$ are dialyzed in the capital city where the three referral hospitals are located, $11(17 \%)$ aged less than 30 years old but $13(20 \%)$ were older than 60 years old hence almost $65 \%$ aged between 30 to 60 years old. Anthropometrically, almost 70\% were in normal range of weight based on Body Mass Index (BMI) calculation, 19\% were in over weight range while only $12 \%$ were in underweight range even as none was obese. A majority population of this study 29 $(44 \%),(\mathrm{n}=66)$ reside in the medium density area, fifteen $(23 \%)$ live-in low-density area, $13(20 \%)$ are located in high density area and nine $(13.6 \%)$ reside in rural area. However, $44(67 \%)$ were unemployed, $14(21 \%)$ are self-employed while seven (7) $(10.6 \%)$ remained at their work as skilled employees.

In respect to monthly income only $27(41 \%)$ can earn more than 100000Rfw 100USD. Consequently, many of these participants 45 $(68 \%)$ got medical help through the particularly medical insurance considered as government/private medical insurance. Approximately $23(35 \%)$ traveled more than $40 \mathrm{kms}$ to reach to the hemodialysis facility at the beginning of their renal replacement therapy modality but $18(27 \%)$ of them shifted from their home to rent a nearby HD facility. Hypertension $26(39 \%)$ is the first leading cause of ESRD followed by diabetes mellitus $21(31 \%)$, glomerular diseases and other causes account for 5(8\%), 14(22\%) cases respectively. On the another hand 50(75\%) have been diagnosed to have an ESRD and started the treatment within a period of less than two years while 13(20\%) have been on dialysis roughly five years instead only three (5\%) came back on dialysis after a graft rejection.

\subsection{Clinical profile and level of hemodialysis adequacy}

Table 2 shows the clinical profile of study participants. More than half of participants $34(62 \%)$ have less than targeted Hemoglobin in ESRD on maintenance HD. 19 (29\%) had normal blood hemoglobin targeted in ESRD patients on maintenance HD ranging between of $10.5 \mathrm{~g}$ to $12.5 \mathrm{~g}$ per dl whilst $13(20 \%)$ had a hemoglobin level greater than $12.5 \mathrm{~g}$ per dl. However, the results from this study demonstrate that participants with less than targeted Hemoglobin level should take the EPO stimulating agent. Thus approximately 45 (70\%) are received EPO stimulants instead $22(30 \%)$ did not. Central venous catheter (CVC) remains the vascular access for the majority 50 (76\%), 15(24\%) had the Arterio-Venous Fistulas (AVF). Forty four (67\%) underwent HD with blood flow rate ranging from 200 to 300 mls per minute, 19(29\%) blood flowed at 300 to $400 \mathrm{mls}$ per minute. In regards of clinical manifestation 23 (35\%) presented high blood pressure, $22(30 \%)$ had normal range of blood pressure and $21(32 \%)$ had very frustrating blood pressure.

Table 2: Clinical Characteristics and Hemodialysis Adequacy. (N=66)

\begin{tabular}{lll}
\hline a. $\quad$ Clinical characteristics & \\
\hline Haemoglobin levels & & $10.5 \pm 1.93(\mathrm{~g} / \mathrm{dl})$ \\
Potassium level & $5.2 \pm 0.93(\mathrm{mmol} / \mathrm{l})$ \\
Creatinine levels & & $559.7 \pm 217.95(\mu \mathrm{mo} / \mathrm{l})$ \\
Blood flow rate & $303 \pm 30.77(\mathrm{mls} / \mathrm{min})$ & \\
& & $33(50.0)$ \\
& & $9(14)$ \\
Frequency of taking erythropoietin (EPO) & Every HD session & $2(3.0)$ \\
& Once in a week & $22(33.0)$ \\
EPO root of administration & Once in two weeks & $21(32)$ \\
& Not taken & $40(60)$ \\
\hline
\end{tabular}




\begin{tabular}{|c|c|c|}
\hline \multirow{4}{*}{ Blood pressure levels } & Taking EPO via Sc & $5(8)$ \\
\hline & Very high BP & $23(35)$ \\
\hline & BP don't frustrate often & $21(32)$ \\
\hline & Normal BP & $22(30)$ \\
\hline \multirow{3}{*}{ Type of vascular access used in HD } & Central venous catheter (CVC) & $50(76)$ \\
\hline & Arterio-venous fistulae (AVF) & $15(23)$ \\
\hline & Arterio venous graft & $1(1)$ \\
\hline \multirow{4}{*}{ Blood flow rate } & BFR between 100 to $200 \mathrm{mls} / \mathrm{min}$ & $1(1)$ \\
\hline & BFR between 200 to $300 \mathrm{mls} / \mathrm{min}$ & $44(67)$ \\
\hline & BFR between 300 to $400 \mathrm{mls} / \mathrm{min}$ & $19(29)$ \\
\hline & BFR greater than $400 \mathrm{mls} / \mathrm{min}$ & $2(3)$ \\
\hline
\end{tabular}

In concern of hemodialysis adequacy, the mean of adequacy of HD in the patients under the study was $1.26 \pm 0.34$ the range of HDA for the entire study population was 1.60. The minimum of dialysis adequacy was 0.50 and maximum was 2.1.Majority of the participants 41 $(62 \%)$ had optimal kt/v of equal and greater than to $1.2,19(29 \%)$ had near optimal HDA (0.8 - 1.2kt/v) whilst (6) six (9\%) had less than optimal $\mathrm{HDA}(\mathrm{kt} / \mathrm{v}<0.8)$; males experienced the better kt/v than females at rate of $66 \%$ to $53 \%$ respectively.

\begin{tabular}{|c|c|c|c|}
\hline \multicolumn{4}{|c|}{ a. Level of hemodialysis adequacy } \\
\hline Variables & Kt/v values & Frequency $(\%)$ & Level of dialysis adequacy \\
\hline $\mathrm{Kt} / \mathrm{v}$ less than 0.8 & $\begin{array}{c}.05 \\
0.60 \\
0.7\end{array}$ & $\begin{array}{l}1(1.5) \\
2(3.0) \\
3(4.5)\end{array}$ & Less than optimal HDA \\
\hline $\mathrm{Kt} / \mathrm{v} 0.8$ to 1.19 & $\begin{array}{l}0.80 \\
0.90 \\
1.00 \\
1.07 \\
1.09 \\
1.10 \\
1.17 \\
1.18 \\
1.19 \\
\end{array}$ & $\begin{array}{c}1(1.5) \\
1(1.5) \\
4(6.1) \\
1(1.5) \\
1(1.5) \\
7(10.6) \\
1(1.5) \\
1(1.5) \\
2(3.0) \\
\end{array}$ & Near optimal HDA \\
\hline $\mathrm{Kt} / \mathrm{v}$ equal/ greater than 1.2 & $\begin{array}{l}1.20 \\
1.25 \\
1.29 \\
1.30 \\
1.32 \\
1.33 \\
1.34 \\
1.35 \\
1.40 \\
1.50 \\
1.60 \\
1.70 \\
1.80 \\
2.00 \\
2.10\end{array}$ & $\begin{array}{c}6(9.1) \\
1(1.5) \\
1(1.5) \\
10(15.2) \\
1(1.5) \\
1(1.5) \\
1(1.5) \\
2(3.0) \\
5(7.6) \\
2(3.0) \\
3(4.5) \\
2(3.0) \\
1(1.5) \\
3(4.5) \\
2(3.0)\end{array}$ & Optimal HDA \\
\hline
\end{tabular}

\subsection{Factors related to hemodialysis adequacy}

Table 3 shows factors related to HDA. On the subject of the adherence to HD treatment $46(70 \%)$ afford the thrice weekly hemodialysis while $17(26 \%)$ underwent twice weekly hemodialysis session and $4 \%$ are neither comply to thrice nor to twice weekly regimen. Sixtyfour $(97 \%)$ last 4 hours of time for their dialysis session while two (3\%) were treated less than three hours per session. However, 12 $(12 \%)$ Shortened their hemodialysis session whom greater than $10(15 \%)$ Shortened at least one session during the previous month when the study was conducted. Furthermore, only a half 34 (51\%) did not miss any session for the previous month when the data was conducting, that means $49 \%$ reported not to miss any dialysis session. Sixty (91\%) saw their schedule as convenient for their treatment option while six $(9 \%)$ considered their schedule as a barrier.

Table3: Factors Related to Hemodialysis Adequacy ( $\mathrm{N}=66)$

\begin{tabular}{lll}
\hline Patients knowledge related factors & & Frequency (\%) \\
\hline Variables & Sub-variables & $5(8)$ \\
& Additional weight for more than $3.1 \mathrm{kgs}$ & $23(35)$ \\
Interdialytic weight gain & Additional weight from $2.1 \mathrm{kgs}$ to $3 \mathrm{kgs}$ & $22(33)$ \\
& Additional weight from $1.1 \mathrm{~kg}$ to $2 \mathrm{kgs}$ & $16(24)$ \\
\hline
\end{tabular}


Information about kt/v

Experience about their potassium levels

\section{Health care providers related factors}

\section{Variables}

Frequency in monitoring patients' blood

Feedback about the results from lab

Information about proper nutrition

Information about fluids restriction

Information about HAD

\section{Adherence to the hemodialysis related factors}

\section{Variables}

Compliance to Prescription of HD sessions per week

\section{HD treatment hours}

Shortening of dialysis time during last month

\section{Convenient about the scheduled time for HD}

Education to comply with the time given for HD treatmen

Difficulty in staying the prescribed time for HD treatment

Missing session during last month
Having information about kt/v

$4(6)$

Do not have information about kt/v

$62(94)$

Not know

Low level

Normal range

29(44)

$3(5)$

High level

\section{Sub-variables}

Who check blood regularly one month

Who do not check blood regularly

Who do not comply blood check unless severe emergency crisis

Who received the feedback from their lab results

Who do not receive the feedback from the lab results

Who have thought about adequate nutrition

Who have not thought about adequate nutrition

Who have thought about fluids restriction

Who have not thought about fluids restriction

Who have thought about HDA

Who have not thought about HDA
Frequency $(\%)$

53(80)

$6(9)$

$7(11)$

$53(80)$

$13(20)$

65(98)

1(2)

64(97)

2(3)

$7(11)$

59(89)

\section{Sub-variables}

Thrice in a week

Twice in a week

Irregular

Who treated 3-4hours/session

Who treated less than 3hours/per session

Who shortened HD treatment last month

Who did not shorten HD treatment last month

Who shortened more than 3 sessions

Who shortened 2 to 3 sessions

Who shortened one session

Who did not shorten any session

Who consider their schedule as convenient

Who do not consider their schedule as inconvenient

Never talked

Talked less frequently

Talked frequently

Most frequently

Very difficult to stay the entire 4hous

Moderate difficult to stay entire 4 hours

A little difficult to stay the entire 4 hour

No difficult to stay the entire 4 hours

Who missed more than three session

Who missed three sessions

Who missed two sessions

Who missed one session

Who did not miss any session
Frequency (\%)

46(70)

$17(26)$

3(4)

64(97)

2(3)

12(18)

54(82)

$1(1.5)$

$1(1.5)$

$10(15)$

$54(82)$

$60(91)$

6(9)

4(6)

15(23)

23(35)

24(36)

16(25)

22(33)

10(15)

18(27)

In respect to patients' knowledge related factors, the most of participants in this study $62(94 \%)$ do not have any information relating to either HDA or $\mathrm{kt} / \mathrm{v}$ but $22(33 \%)$ can manage their interdialytic weight gain at $2 \mathrm{kgs}$ based on their respective dry weight between two consecutive sessions, $23(35 \%)$ manage to come with three kilograms of additional weight while only 5(8\%) cannot manage their interdialytic weight since they came with more than $3.1 \mathrm{kgs}$ between two consecutive sessions. Twenty- nine (44\%) did not know how much potassium that they experiencing often compared to $28(42 \%)$ who experienced normal range of potassium whilst $3(5 \%)$, 6(9\%) experienced low and high level of potassium respectively

In regards of health care providers related factors; greater than 64(97\%) of the participants in this study had enough information about the proper nutrition and fluids restriction as well, yet only $7(11 \%)$ heard information about both dialysis adequacy and the kt/v. 53(80\%) of our participants monitor their blood investigation once in a month contrary to $7(11 \%)$ who do blood check in case of severe emergency crisis ,fortunately 53(80\%) followed up the laboratory results from their blood while 13(20\%) are not aware of the situation of blood results.

\subsection{Factors associated with hemodialysis adequacy}


Table 4 highlights factors associated with hemodialysis adequacy. Factors associated with HDA were name of hospital $(\mathrm{p}=.010)$, age $(\mathrm{p}$ $=.007)$, BMI $(\mathrm{p}=.004)$ and blood pressure level $((\mathrm{p}=.018)$. Moreover, mode of transport and type of drinking water was significantly associated with HDA ( $\mathrm{p}=0.032$ and 0.030 respectively).

Table 4: Factors Associated with Hemodialysis Adequacy $(\mathrm{N}=66)$

\begin{tabular}{lcl}
\hline Variable & Chi squared (value) \\
\hline Hospitals' origins & Pearson Chi-square $(21.587)$ \\
Age & Pearson Chi-square (27.445) \\
BMI & Pearson Chi-square $(19.158)$ \\
Blood pressure levels & Pearson chi-square $(15.87)$ & .001 \\
Area of residence & Pearson Chi-square $(17.946)$ & .007 \\
Means of transport & Pearson Chi-square (8.813) \\
Types of drinking water & Pearson Chi-square (8.925) \\
\hline
\end{tabular}

Table 5 shows that multiple regression analysis was done to reveal all the associated demographic covariates towards HDA. The results highlighted that demographic covariates contributed nearly $49.5 \%$ variance towards HDA with a significant F change of $p=.005$. Moreover, using the beta coefficient shows that hospital of origin, mode of transport, type of drinking water and BIM are contributing negatively to haemodialysis adequacy. However, duration of ESRD, age and blood pressure levels were affecting HDA positively.

Table 5: Multiple Regressions Analysis of the Factors Associated with Hemodialysis Adequacy

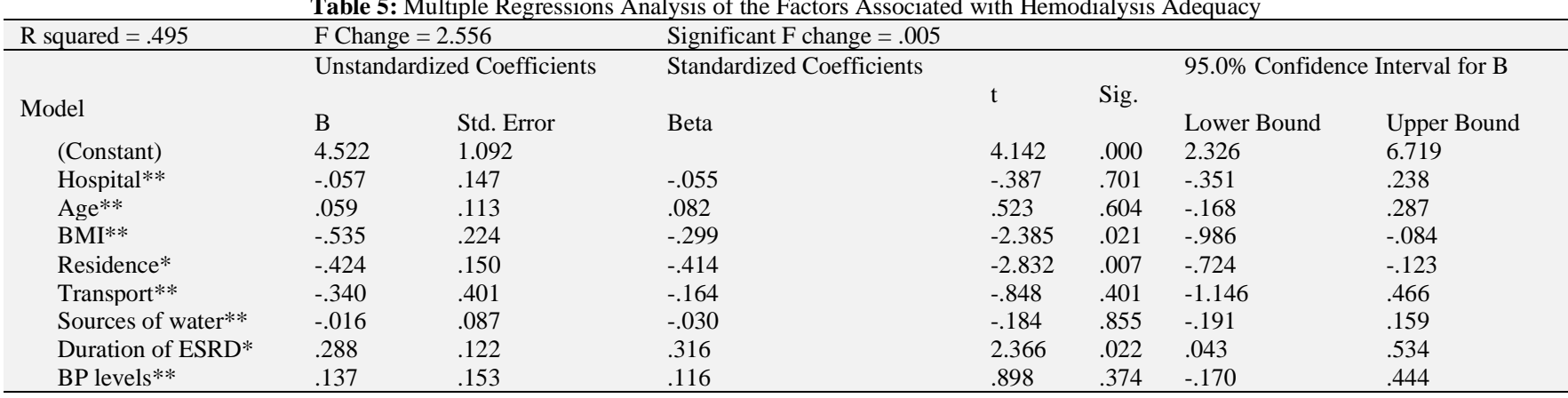

Dependent Variable: Heamodialysis Adequacy.

$(* *)$ : variables that are statically associated with HAD.

(*): variables that are most likely exhibit to HDA.

\section{Discussion}

\subsection{Demographic characteristics}

The HDA is a fundamental for each patient. It improves the outcome of ESRD patients. In this study, the hospital settings significantly exhibit the level of HDA among the participants of this study; this confirms that patients benefited from a higher quality of hemodialysis settings. Our findings proved that males were almost three times to female 47 (71\%), 19 (29\%) respectively. The gender and ESRD patients on maintenance HD have been reported by (Manfred et al. 2014) found fewer women than men undergoing HD treatment contrary to other studies found almost the equal proportion between males and females such as (Hosein et al. 2016), reported 58.60\% to be male and a study by (Ozra et al. 2016) reported $135(66.8 \%)$ were men and $67(33.2 \%)$ were female. Almost $65 \%$ of our participants were between 30 to 60 years old similar to (Hosein et al. 2016) in their study the mean age was 48 years, in another study revealed that the age of the study population was 53 years by (Sheikh \& Ghazaly 2016), consistently to (Adremi et al. 2017) and (Dana et al. 217) reported the mean age of 46 and 54 years respectively. But contrary to a study in Uganda by (Kalyesubula et al. 2017) who found that more than half of patients were over 50 years.

The most causes of ESRD are HTN, DM, Glomerular diseases whereas in our participants hypertension (HTN) accounts (39\%), diabetes mellitus (DM) (31\%), glomerular diseases (8\%) and others causes(unknowns, malaria and polycystic kidney disease (PKD) as well). It was the same in Kenya, where hypertensive sclerosis was the main cause of ESRD (16\%), followed by diabetic nephropathy (15\%), chronic glomerulonephritis (13\%), tubule interstitial/ obstructive (8\%), primary glomerular diseases (6\%), systemic lupus erythematosus (3\%) and polycystic kidney disease (3\%). Consistently to a study by (Naiker et al.2013) noted HTN as a leading cause of ESRD in SSA, ranging from $25 \%$ in Senegal to $29.8 \%$ in Nigeria, $45.6 \%$ in South Africa, and $48.7 \%$ in Ghana, especially in black patients. HTN affects about $25 \%$ of the adult population and is the cause of ESRD in $21 \%$ of patients on RRT in South Africa while in developed countries like USA major causes for ESRD are diabetic nephropathy (43.2\%), HTN (23\%), glomerulonephritis (12.3\%), and polycystic kidney disease (2.9\%), (Somnath, 2016). In Germany HTN and diabetes mellitus (DM) come in front (Girndt \& Markau 2016), Whereas in north Africa major risk factors are interstitial nephritis (14 to 32\%), glomerulonephritis (11 to 24\%), mostly mesangioproliferative and focal segmental sclerosis; diabetes (5 to $20 \%$ ) and nephrosclerosis (5 to $21 \%$ ).

Approximately $65 \%$ of the patients with ESRD in Rwanda travelled more than $40 \mathrm{kms}$ to reach to the hemodialysis facility which means live in rural areas yet many HD facilities located at the capital city; about $60 \%$ can earn only less than 100000 Rwandan Franc [Rwf(100USD)]. Moreover 68\% got medical help through the particularly medical insurance thus most of these respondents cannot afford HD treatment, a Rwandan GDP per capita is 776USD (World Bank,2019) thus for one session of HD costs as a much as USD 100 200 (Taslim 2014). This explains why there are few people with ESRD on maintenance HD because those with community health-based insurance and those without insurance should pay out of pocket for HD treatment. However, most patients with ESRD have to rely on financial support from their extended families, religious organizations and philanthropists to be able to pay for hemodialysis in Rwanda. Many patients with ESRD are denied access to maintenance HD because of rationing policies that limit provision of hemodialysis to patients with a few co-morbidities (Etheredge and June 2017). 


\subsection{Hemodialysis adequacy}

These findings demonstrate that only $62 \%(\mathrm{n}=66)$ had optimal hemodialysis adequacy $(\mathrm{kt} / \mathrm{v}$ equal/greater than 1.2$)$. However, the study conducted by (Ozra et al. 2016) based on kt/v and URR showed 56.4\% of the patients had desirable HDA, in Egypt a study conducted by (Mabrouk \& Ghada, 2016) showed that around $60 \%$ of the study population had Kt/V values less than 1.2. Therefore, these results indicated that the HDA were favorable compared to the mentioned studies. It appears that the increased awareness of the patients and frequent education of the hemodialysis personnel provided favorable conditions; consequently the mean of HDA for the entire population was $1.26 \pm 0.34$; the mode was 1.3.The same values for HDA have been reported as $1.73 \pm 0.41$ (Debowska et al. 2014), 1.72 \pm 0.21 in the study (Ashvandi et al. 2014) and $1.15 \pm 0.31$ in the study (Samakoosh et al. 2013) consistently to (Heba et al. 2014) the mean Kt/V for the studied patients were $1.06 \pm 0.05$.

\subsection{Factors associated with hemodialysis adequacy}

Until recently, elderly patients were offered renal replacement therapy worldwide. In the current study age is negatively associated with the HDA. A study conducted by (Ozra et al. 2016) noted that HDA had an inverse relationship with the variables of age contrary to a study conducted by (Heba et al. 2014) where was no significant association between HDA and any of the variables such as sex, age, presence of chronic diseases or BMI. The study conducted by (Tezcan et al. 2016) on relationship between the target dose of HDA and nutritional assessment showed that prevalence of malnutrition in patients with target dose hemodialysis $(\mathrm{Kt} / \mathrm{V} \geq 1.4)$ was significantly higher according to body mass index (BMI). Similar as the results from this study showed that BMI associated negatively with HDA but (Heba et al. 2014) reported insignificant association between BMI and HDA.

The results from this study revealed that mean of transport and type of drinking water which goes hand in hand with monthly income exhibit negative impacts to the results of HDA, those parameters are depressing significantly with HDA. Nevertheless, no literature discovered discussing about the same variables, although most data available currently emanates from developed world and this may not accurately reflect to our situation due to major socio-cultural, economic and environmental differences. Along with other factors affecting the adequacy of hemodialysis was blood pressure. The results of this study showed a positive relationship with HDA since the normal the blood pressure during HD, the greater optimal HDA. Yet (Ozra et al. 2016) studies showed a significant correlation between HDA and pre-HD systolic blood pressure and diastolic blood pressure. Taking EPO, type of vascular access, blood flow rate, having knowledge about proper nutrition, adequate fluids intake and having information about HDA are not significantly related to HDA in this current study; probably because most of all participants have been dialyzed with the better blood flow rate in all settings with a mean BFR of $303 \pm 30.77$ ( $\mathrm{mls} / \mathrm{min})$. Again, the mean hemoglobin levels in the entire population were $10.5 \pm 1.93(\mathrm{~g} / \mathrm{dl})$ which is a minimum range recommended level of hemoglobin for ESRD on maintenance HD.

\section{Conclusion}

The mean of HDA of dialysis in the patients under the study was $1.26 \pm 0.34$ with most participants (62\%) achieving had optimal HDA $\mathrm{kt} / \mathrm{v}$ of equal or greater than to 1.2. Factors associated with HDA were predominantly demographic characteristics. Therefore, further research inquiry is needed on other factors which include technical aspects to establish their association with hemodialysis adequacy. Additionally, a cohort study to assess the impact of hemodialysis adequacy on quality of life among end stage renal disease patients should be conducted in the similar settings.

\section{Acknowledgements}

We would like to thank the study site and participants.

\section{References}

[1] Caravaca-Fontán, F., Azevedo, L., Luna, E. and Caravaca, F., 2017. Patterns of progression of chronic kidney disease at later stages. Clinical kidney journal, 11(2), pp.246-253. https://doi.org/10.1093/ckj/sfx083.

[2] Chandrashekar,A., Ramakrishnan, S. and Rangarajan, D., 2014.Survival analysis of patients on maintenance hemodialysis. Indian journal of nephrology, 24(4), p.206. https://doi.org/10.4103/0971-4065.132985.

[3] Chowdhury, T.A., Iqbal, S., Talukder, U.S., Ananna, M.A., Bhuiyan, A.M.M., Billah, M., Rahim, M.A., Samad, T. and Hossain, R.M., 2017. A study on knowledge of patients with end stage renal disease towards dialysis in a tertiary care hospital in Dhaka city. IMC Journal of Medical Science, 11(1), pp.11-14. https://doi.org/10.3329/imcjms.v11i1.31932.

[4] ElHafeez, S.A., Bolignano, D., D’Arrigo, G., Dounousi, E., Tripepi, G. and Zoccali, C., 2018. Prevalence and burden of chronic kidney disease among the general population and high-risk groups in Africa: a systematic review. BMJ open, 8(1), p.e015069. https://doi.org/10.1136/bmjopen2016-015069.

[5] Etheredge, H. and Fabian, J., 2017, September. Challenges in expanding access to dialysis in South Africa-expensive modalities, cost constraints and human rights. In Healthcare (Vol. 5, No. 3, p. 38). Multidisciplinary Digital Publishing Institute. https://doi.org/10.3390/healthcare5030038.

[6] Fernandez-Prado, R., Fernandez-Fernandez, B. and Ortiz, A., 2018. Women and renal replacement therapy in Europe: lower incidence, equal access to transplantation, longer survival than men. Clinical kidney journal, 11(1), pp.1-6. https://doi.org/10.1093/ckj/sfx154.

[7] George, C., Mogueo, A., Okpechi, I., Echouffo-Tcheugui, J.B. and Kengne, A.P., 2017. Chronic kidney disease in low-income to middle-income countries: the case for increased screening. BMJ global health, 2(2), p.e000256. https://doi.org/10.1136/bmjgh-2016-000256.

[8] Girndt, M., Trocchi, P., Scheidt-Nave, C., Markau, S. and Stang, A., 2016. The Prevalence of Renal Failure: Results from the German Health Interview and Examination Survey for Adults, 2008-2011 (DEGS1). Deutsches Ärzteblatt International, 113(6), p.85. https://doi.org/10.3238/arztebl.2016.0085.

[9] Glidewell, L., Boocock, S., Pine, K., Campbell, R., Hackett, J., Gill, S. and Wilkie, M., 2013. Using behavioral theories to optimize shared hemodialysis care: a qualitative intervention development study of patient and professional experience. Implementation Science, 8(1), p.118. https://doi.org/10.1186/1748-5908-8-118.

[10] Haghighi, M.J., Shahdadi, H., Abdollahimohammad, A. and Moghadam, M.P., 2016. The effect of low-flux and high-flux filters on adequacy and complications during hemodialysis of patients. Der Pharmacia Lettre, 8(19), pp.395-399. https://doi.org/10.1186/s12882-017-0664-9.

[11] Hauber, B., Caloyeras, J., Posner, J., Brommage, D., Tzivelekis, S. and Pollock, A., 2017. Hemodialysis patients' preferences for the management of anemia. BMC nephrology, 18(1), p.253 https://doi.org/10.1186/s12882-017-0664-9. 
[12] Hod, T., Patibandla, B.K., Vin, Y., Brown, R.S. and Goldfarb-Rumyantzev, A.S., 2014. Arteriovenous fistula placement in the elderly: when is the optimal time? Journal of the American Society of Nephrology, pp.ASN-2013070740. https://doi.org/10.1681/ASN.2013070740.

[13] Ibrahim, S., Hossam, M. and Belal, D., 2015. Study of non-compliance among chronic hemodialysis patients and its impact on patients' outcomes. Saudi Journal of Kidney Diseases and Transplantation, 26(2), p.243 https://doi.org/10.4103/1319-2442.152405.

[14] Iraq. Meyer, T.W., Sirich, T.L., Fong, K.D., Plummer, N.S., Shafi, T., Hwang, S., Banerjee, T., Zhu, Y., Powe, N.R., Hai, X. and Hostetter, T.H., 2016. Kt/Vurea and nonurea small solute levels in the hemodialysis study. Journal of the American Society of Nephrology, pp.ASN-2015091035. https://doi.org/10.1681/ASN.2015091035.

[15] Jacob, s., 2016. The relationship between hemodialysis patients' fluid compliance and selected socio-demographic factors in northern alberta, canada (doctoral dissertation, university of northern BritishColumbia https://doi.org/10.24124/2016/1235.

[16] Jebraeily, M., Safdari, R., Rahimi, B., Makhdoomi, K. and Ghazisaeidi, M., 2018. The application of intelligent information systems in hemodialysis adequacy promotion. Journal of Renal Injury Prevention, 7(2), pp.64-68. https://doi.org/10.15171/jrip.2018.16.

[17] Jin, D.C., 2015. Major changes and improvements of dialysis therapy in Korea: review of end-stage renal disease registry. The Korean journal of internal medicine, 30(1), p.17. https://doi.org/10.3904/kjim.2015.30.1.17.

[18] Kramer, A., 2011. Epidemiology and outcomes of renal replacement therapy: results from the ERA-EDTA registry. Universiteit van Amsterdam.[see https://hdl.handle.net/11245/1.385818]

[19] Kulkarni, M.J., Jamale, T., Hase, N.K., Jagdish, P.K., Keskar, V., Patil, H., Shete, A. and Patil, C., 2015. A cross-sectional study of dialysis practice-patterns in patients with chronic kidney disease on maintenance hemodialysis. Saudi Journal of Kidney Diseases and Transplantation, 26(5), p.1050. https://doi.org/10.4103/1319-2442.164607.

[20] Lertdumrongluk, P., Streja, E., Rhee, C.M., Park, J., Arah, O.A., Brunelli, S.M., Nissenson, A.R., Gillen, D. and Kalantar-Zadeh, K., 2014. Dose of hemodialysis and survival: a marginal structural model analysis. American journal of nephrology, 39(5), pp.383-391. https://doi.org/10.1159/000362285.

[21] Liu, F.X., Rutherford, P., Smoyer-Tomic, K., Prichard, S. and Laplante, S., 2015. A global overview of renal registries: a systematic review. BMC nephrology, 16(1), p.31 https://doi.org/10.1186/s12882-015-0028-2.

[22] Liyanage, T., Ninomiya, T., Jha, V., Neal, B., Patrice, H.M., Okpechi, I., Zhao, M.H., Lv, J., Garg, A.X., Knight, J. and Rodgers, A., 2015. Worldwide access to treatment for end-stage kidney disease: a systematic review. The Lancet, 385(9981), pp.1975-1982. https://doi.org/10.1016/S0140-6736(14)61601-9.

[23] Lu R, Estremadoyro C, Chen X, Zhu M, Ribeiro LC, Yan Y, Brendolan A, Fang W, Crepaldi C, Ni Z, Gu L. Hemodialysis versus peritoneal dialysis: an observational study in two international centers. The International journal of artificial organs. 2018 Jan;41(1):58-65. https://doi.org/10.5301/ijao.5000656.

[24] Mimura, I., Tanaka, T. and Nangaku, M., 2015. How the Target Hemoglobin of Renal Anemia Should Be? Nephron, 131(3), pp.202-209. https://doi.org/10.1159/000440849.

[25] Mukakarangwa, M. C., Chironda, G., Bhengu, B., \& Katende, G. (2018). Adherence to hemodialysis and associated factors among end stage renal disease patients at selected nephrology units in rwanda: a descriptive cross-sectional study. Nursing research and practice, 2018. https://doi.org/10.1155/2018/4372716.

[26] Mushi, L., Marschall, P. and Fleßa, S., 2015. The cost of dialysis in low and middle-income countries: a systematic review. BMC health services research, 15(1), p.506. https://doi.org/10.1186/s12913-015-1166-8.

[27] Nafar, M., Samavat, S., Khoshdel, A. and Abedi, B.A., 2017. Dialysis Adequacy, Dialyzer Clearance, and Strategies to Achieve Target: A Nationwide Multicenter Study. Nephro-Urology Monthly, 9(1). https://doi.org/10.5812/numonthly.42769.

[28] Naicker, S. and Ashuntantang, G., 2017. End stage renal disease in Sub-Saharan Africa. In Chronic Kidney Disease in Disadvantaged Populations (pp. 125-137). https://doi.org/10.1016/B978-0-12-804311-0.00014-5.

[29] Naicker, S. and Ashuntantang, G., 2017. End stage renal disease in Sub-Saharan Africa. In Chronic Kidney Disease in Disadvantaged Populations (pp. 125-137). https://doi.org/10.1016/B978-0-12-804311-0.00014-5.

[30] Oluyombo, R., Okunola, O.O., Olanrewaju, T.O., Soje, M.O., Obajolowo, O.O. and Ayorinde, M.A., 2014. Challenges of hemodialysis in a new renal care center: call for sustainability and improved outcome. International journal of nephrology and renovascular disease, 7 , p.347. https://doi.org/10.2147/IJNRD.S65835.

[31] Paiva, C.E., Barroso, E.M., Carneseca, E.C., de Pádua Souza, C., dos Santos, F.T., López, R.V.M. and Paiva, S.B.R., 2014. A critical analysis of test-retest reliability in instrument validation studies of cancer patients under palliative care: a systematic review. BMC medical research methodology, 14(1), p.8. https://doi.org/10.1186/1471-2288-14-8.

[32] Rees, L., 2018. Assessment of dialysis adequacy: beyond urea kinetic measurements. Pediatric Nephrology, pp.1-9. https://doi.org/10.1007/s00467-018-3914-6.

[33] Rezaiee, O., Shahgholian, N. and Shahidi, S., 2016. Assessment of hemodialysis adequacy and its relationship with individual and personal factors. Iranian journal of nursing and midwifery research, 21(6), p.577 https://doi.org/10.4103/1735-9066.197673.

[34] Ross, E.A., Paugh-Miller, J.L. and Nappo, R.W., 2017. Interventions to improve hemodialysis adequacy: protocols based on real-time monitoring of dialysate solute clearance. Clinical Kidney Journal, 11(3), pp.394-399. https://doi.org/10.1093/ckj/sfx110.

[35] Saleh, T., Sumida, K., Molnar, M.Z., Potukuchi, P.K., Thomas, F., Lu, J.L., Gyamlani, G.G., Streja, E., Kalantar-Zadeh, K. and Kovesdy, C.P., 2017. Effect of age on the Association of Vascular Access Type with mortality in a cohort of incident end-stage renal disease patients. Nephron, 137(1), pp.57-63. https://doi.org/10.1159/000477271.

[36] Santoro, D., Benedetto, F., Mondello, P., Pipitò, N., Barillà, D., Spinelli, F., Ricciardi, C.A., Cernaro, V. and Buemi, M., 2014. Vascular access for hemodialysis: current https://doi.org/10.2147/IJNRD.S46643.

[37] Shahdadi, H., Balouchi, A., Sepehri, Z., Rafiemanesh, H., Magbri, A., Keikhaie, F., Shahakzehi, A. and Sarjou, A.A., 2016. Factors Affecting Hemodialysis Adequacy in Cohort of Iranian Patient with End Stage Renal Disease. Global journal of health science, 8(8), p.50. https://doi.org/10.5539/gjhs.v8n8p50.

[38] Sharif, D.A., Awn, A.H., Murad, K.M. and Meran, I.M., Demographic and Characteristic Distribution of End Stage Renal Failure in Sulaimani Governorate, Kurdistan Region,

[39] Shibiru, T., Gudina, E. K., Habte, B., Deribew, A., \& Agonafer, T. (2013). Survival patterns of patients on maintenance hemodialysis for end stage renal disease in Ethiopia: summary of 91 cases. BMC nephrology, 14(1), 1-6. https://doi.org/10.1186/1471-2369-14-127.

[40] Slinin, Y., Greer, N., Ishani, A., MacDonald, R., Olson, C., Rutks, I. and Wilt, T.J., 2015. Timing of dialysis initiation, duration and frequency of hemodialysis sessions, and membrane flux: a systematic review for a KDOQI clinical practice guideline. American Journal of Kidney Diseases, 66(5), pp.823-836. https://doi.org/10.1053/j.ajkd.2014.11.031.

[41] Sun, Y., Wang, Y., Yu, W., Zhuo, Y., Yuan, Q. and Wu, X., 2018. Association of Dose and Frequency on the Survival of Patients on Maintenance of Hemodialysis in China: A Kaplan-Meier and Cox-Proportional Hazard Model Analysis. Medical science monitor: international medical journal of experimental and clinical research, 24, p.5329. https://doi.org/10.12659/MSM.909404.

[42] Tsai, W.C., Wu, H.Y., Peng, Y.S., Ko, M.J., Wu, M.S., Hung, K.Y., Wu, K.D., Chu, T.S. and Chien, K.L., 2016. Risk factors for development and progression of chronic kidney disease: a systematic review and exploratory meta-analysis. Medicine, 95(11). https://doi.org/10.1097/MD.0000000000003013.

[43] Wright, D.G., Wright, E.C., Narva, A.S., Noguchi, C.T. and Eggers, P.W., 2015. Association of erythropoietin dose and route of administration with clinical outcomes for patients on hemodialysis in the United States. Clinical Journal of the American Society of Nephrology, pp.CJN01590215 https://doi.org/10.2215/CJN.01590215. 
[44] Younis, M., Jabr, S., Al-Khatib, A., Forgione, D., Hartmann, M. and Kisa, A., 2015. A cost analysis of kidney replacement therapy options in Palestine. INQUIRY: The Journal of Health Care Organization, Provision, and Financing, 52, p.0046958015573494 https://doi.org/10.1177/0046958015573494.

[45] Youssouf, S., 2017. Outcomes of a Programme of Quality Improvement to Improve Attainment of Clinical Indicators in a Chronic Dialysis Population (Doctoral dissertation, University of Manchester).

[46] Zhang, M., Wang, M., Li, H., Yu, P., Yuan, L., Hao, C., Chen, J. and Kalantar-Zadeh, K., 2014. Association of initial twice-weekly hemodialysis treatment with preservation of residual kidney function in ESRD patients. American journal of nephrology, 40(2), pp.140-150 https://doi.org/10.1159/000365819. 